\title{
Assessing The Completeness of Periodontal Disease Documentation in The EHR: A First Step in Measuring The Quality of Care
}

\section{Joanna Mullins}

Willamette Dental Group, Portland, OR

Alfa Yansane

University of California, San Francisco - School of Dentistry, San Francisco, CA

\section{Shwetha Kumar}

The University of Texas Health Science Center - School of Dentistry, Houston, TX

\section{Suhasini Bangar}

The University of Texas Health Science Center - School of Dentistry, Houston, TX

\section{Ana Neumann}

The University of Texas Health Science Center - School of Dentistry, Houston, TX

Todd Johnson

The University of Texas Health Science Center - School of Dentistry, Houston, TX

\section{Gregory Olson}

The University of Texas Health Science Center - School of Dentistry, Houston, TX

\section{Krishna Kumar Kookal}

The University of Texas Health Science Center - School of Dentistry, Houston, TX

\section{Emily Sedlock}

The University of Texas Health Science Center - School of Dentistry, Houston, TX

\section{Aram Kim}

Harvard School of Dental Medicine, Boston, MA

\section{Elizabeth Mertz}

University of California, San Francisco - School of Dentistry, San Francisco, CA

\section{Ryan Brandon}

Willamette Dental Group, Portland, OR

\section{Kristen Simmons}

Willamette Dental Group, Portland, OR

Joel White

University of California, San Francisco - School of Dentistry, San Francisco, CA

\section{Elsbeth Kalenderian}

University of California, San Francisco - School of Dentistry, San Francisco, CA

Muhammad Walji ( $D$ Muhammad.F.Walji@uth.tmc.edu )

The University of Texas Health Science Center - School of Dentistry, Houston, TX

\section{Research Article}

Keywords: Quality, Dental Quality Measures (DQMs), Value, EHR, Periodontal Disease, Periodontal Risk Assessment 
Posted Date: February 16th, 2021

DOI: https://doi.org/10.21203/rs.3.rs-156335/v1

License: () This work is licensed under a Creative Commons Attribution 4.0 International License. Read Full License 


\section{Abstract}

Background: Our objective was to measure the proportion of patients for which comprehensive periodontal charting, periodontal disease risk factors (diabetes status, tobacco use, and oral home care compliance), and periodontal diagnoses were documented in the electronic health record (EHR). We developed an EHR-based quality measure to assess how well four dental institutions documented periodontal disease-related information. An automated database script was developed and implemented in the EHR at each institution. The measure was validated by comparing the findings from the measure with a manual review of charts.

Results:-The overall measure scores varied significantly across the four institutions (site $1=20.47 \%$, site $2=0.97 \%$, site $3=22.27 \%$ site $4=99.49 \%$, $p$-value $<0.0001$ ). The largest gaps in documentation were related to periodontal diagnoses and capturing oral homecare compliance. A random sample of 1,224 charts were manually reviewed and showed excellent validity when compared with the data generated from the EHR-based measure (Sensitivity, Specificity, PPV, and NPV $>80 \%)$.

Conclusion: Our results demonstrate the feasibility of developing automated data extraction scripts using structured data from EHRs, and successfully implementing these to identify and measure the periodontal documentation completeness within and across different dental institutions.

\section{Introduction}

Modern-day healthcare places an increased emphasis on quality improvement to achieve better patient outcomes. $(1,2)$ Quality measures act as observable tools to evaluate the performance of healthcare processes against established standards of care, both at the program and practice level.(3) Alternative payment methods, e.g., Pay for Performance and "Value Based Care", were in part developed to incentivize providers to achieve improved patient outcomes at lower costs. Regardless of the payment model in vogue, the importance of healthcare quality and the need for accurate and valid quality measures that can quantify healthcare performance are evident.(4)

The Dental Quality Alliance (DQA)(5) has played a vital role in the development and promotion of dental quality measures (DQMs).(5-7) Although the current methods of DQMs rely heavily on claims-based measures/administrative data, there has been a move towards harnessing Electronic Health Record (EHR) data to identify and report quality measures in dentistry. $(8,9)$ The passing of the Health Information Technology for Economic and Clinical Health (HITECH) Act aimed to encourage adopting and promoting of "meaningful use" of EHRs and has paved the way to developing EHR-based quality measures,(10) including dentistry.(11) The inherently rich content of EHR data, which consists of critical patient-level information, makes it an excellent resource to measure healthcare performance. Numerous studies have reported high validity of electronic quality measures for assessing dental care.(12-14)

Periodontal disease is a chronic inflammation of soft tissues and alveolar bone surrounding the teeth; when left untreated, the progressive loss of attachment may increase in tooth mobility and premature tooth loss.(15) Based on the 2009-2010 National Health and Nutrition Examination Survey (NHANES) cycle, $47 \%$ of the total US adult population suffered from periodontitis, while $64 \%$ of adults age 65 and older had either moderate or severe periodontitis.(16) Hostmicrobial interactions are key factors in the pathogenesis of periodontitis, while certain risk factors including smoking, poor oral hygiene, and diabetes are likely to increase host susceptibility. $(17,18)$ Clinical periodontal status parameters, including scores of supragingival plaque, bleeding, suppuration and probing depth as well as tissue appearance can be useful indicators of periodontal disease presence and progression.(19) Identifying an individual's risk factors could further enhance evaluation and monitoring of the susceptibility for disease progression, thereby optimizing treatment 
strategies. $(20,21)$ Based on this premise, developing and using accurate, reliable, and standardized risk assessment tools are paramount.(17), (22)

In 2015, the DQA reported as part of its environmental scan, four periodontal health measures in use at the practice level,(23) which represent the accepted standard of periodontal care among oral health care providers.(24) The DQA itself has one periodontal measure under development, which assesses the utilization and quality of periodontal care. $(23,25)$ While there are no universally accepted periodontal disease risk assessment (PDRA) tools in dentistry, there has been a movement to develop assessment tools that evaluate the risk for developing periodontal disease based on prespecified conditions. $(22,26,27)$ Currently, there is limited information available about the generalizability of these measures. $(28,29)$

As the first step towards our longer-term goal of determining the appropriateness of treatment and the outcomes of care, the aim of this study was to develop an EHR-based quality measure to determine how thoroughly different dental institutions document basic periodontal information. Our objective was to measure the proportion of patients for which a comprehensive periodontal charting, periodontal disease risk factors (diabetes status, tobacco use, and oral home care compliance), (22,30-32) and periodontal diagnoses were documented in the EHR.

\section{Methods}

Our study collected data from three academic institutions and one large accountable dental care organization that all used the same EHR system (Exan, Coquitlam, BC, Canada). Our research team, comprised of clinicians, informaticians, public health dentists, and statisticians, developed the following measure to assess and document periodontal disease risk and diagnosis.

Study population: We designed our measures while considering existing practice guidelines regarding assessing periodontal risks. The denominator of the measure included patients 16 years of age or older and had at least one completed or in progress comprehensive/periodic/or periodontal exam (D0120/D0150/D0180) in the reporting year (Figure 1a). The numerator included patients who had a completed periodontal probing charting, an assessment of all three periodontal disease risk factors (diabetes status, tobacco use, and oral home care compliance), and a periodontal diagnosis within six weeks of their comprehensive/periodic/or periodontal exam (Figure 1b).

\section{Approach for Testing and Validating the Automated Query}

Data from the 2015 calendar year was used for testing and validation purposes using the following steps:

Step 1:Measure automation (automated query): All test sites generated the sampling frame from their EHR using the same Structured Query Language (SQL) script, assuring all patients who were eligible would be included in both the denominator and the numerator.

Step 2: Sample size estimation: We estimated the sample size using the proportion of patients who received periodontal charting, periodontal risk assessment, and periodontal diagnoses for each site during the reporting period as derived from the automated query. We calculated the required sample size for a manual review with a precision of $5 \%$ around the expected effect size at the $95 \%$ confidence interval $(\mathrm{Cl})$ level.

Step 3:MeasureValidation: We validated the automated query performance through a manual chart review, which served as the gold standard. In our earlier studies, $(13,14,33,34)$ we effectively calibrated two trained reviewers at each site, by calculating the interrater reliability using 50 manual chart audits. When both reviewers achieved $>80 \%$ 
agreement,(35) we proceeded with single reviews to complete the remaining charts, calculated the sensitivity, specificity, positive predictive value, and negative predictive value of the automated query.

Step 4:Measure score: EHR-measure proportions were calculated as a percentage of numerator/denominator for each site.

Step 5:Statistical Analyses: By site, descriptive analysis was employed for all measure scores. The frequencies and percent for the total number of patients who received tobacco, homecare (defined as the presence of heavy plaque), and diabetes screenings, had comprehensive periodontal charting and received periodontal diagnoses were calculated. Line graphs were generated to show site variations of the measure scores over time, and bar charts were generated to show the site distributions. In order to determine whether there were statistically significant differences between the measures scores calculated by manual review and those calculated by the query results, an independent sample hypothesis test was performed. All tests were conducted at the standard significance level of $0.05(a=0.05)$ and all analysis used Stata Statistical software release 14 for StataCorp LP. After the validation process, the measures were run again for three additional years $(2016,2017$, and 2018).

\section{Results}

The validity of the measure score was established using standard diagnostics (sensitivity, specificity, positive predicted value (PPV), and negative predictive value (NPV)). 205 charts were manually reviewed at Site 1, 323 charts at site 2, 312 charts at site 3 , and 384 charts at site 4 . The score derived from the manual chart reviews at each site was compared with the score calculated from the automated query. Overall, the diagnostic tests showed a high sensitivity, specificity, PPV, and NPV across all sites (Table 1). Site 2 had the lowest PPV among the sites, which we attributed to the low counts of patients in the denominator.

Table 2 summarizes the results of the automated query across the four sites for the overall measure score, and each of its constituent components. For example, for the year 2018, Site 1 had an "Overall Measure" score of 20.47\%, indicating that only 1 in 5 charts contained all the necessary information; comprehensive periodontal probing chart, periodontal risk factors, and a periodontal diagnosis. To help identify gaps, Table 2 also shows the component measures comprising the full score. At Site 1 for the year $2018,42.71 \%$ of the 6452 patients in the denominator had a periodontal diagnosis documented, $62.95 \%$ had a comprehensive periodontal chart, and $40.07 \%$ had all three of the periodontal risk factors assessed. Of the periodontal risk factors assessed for Site 1 in 2018, homecare was less frequently documented (45.29\%), compared to diabetes (67.37\%) and tobacco status $(68.92 \%)$.

As shown in Figure 2, the performance on the overall and component measures varied across the four sites. Using a chi-squared test for homogeneity of proportions, there were significant variations in the measure score between sites across all years. Site 4 significantly outperformed the other three sites, while Site 2 consistently scored the lowest over the study period. (2015: $c^{2}=1.2 \mathrm{e} 05, \mathrm{p}$-value $<0.0001$; Site $3: c^{2}=1.2 \mathrm{e} 05$, p-value $<0.0001$; Site $1: c^{2}=1.4 \mathrm{e} 05, \mathrm{p}$-value $<0.0001$; Site 4: $c^{2}=1.6 \mathrm{e} 0, \mathrm{p}$-value $\left.<0.0001\right)$.

The chi-squared test for homogeneity of proportions, found significant variations in the overall measure score over time within the same site. For Site 1, the chi-squared test showed that the overall measure score in year 2017 was

significantly higher than in other years, and there was a 4.03\% decrease over the study period (Site 1: $c^{2}=132.6, p$-value $<0.0001)$. For Site 2 the chi-squared test shows the measure scores in $2016(1.97 \%)$ were significantly higher than the other years for Site 2 (Site 2: $c^{2}=34.7, p$-value $<0.001$ ). Site 2 experienced a $0.3 \%$ increase over the 4 -year study period. For Site 3, the chi-squared test shows the measures scores in 2015 were significantly higher than those in other years 
(Site 3: $c^{2}=178 ., p$-value $<0.0001$ ). Lastly, the chi-squared test showed that Site 4 measure scores in 2018 outperformed all other years (Site $4: c^{2}=221.3$, p-value $<0.0001$ ), the scores remained relatively constant over time.

\section{Discussion}

Our results demonstrate the feasibility of developing automated data extraction scripts using structured data from EHRs, and successfully implementing these to identify and measure the periodontal documentation completeness within and across different dental institutions. Even though all four institutions included in the study used the same EHR and the same standardized diagnostic terminology (SNODDS), $(36,37)$ we saw a large variation in how they performed on the measure. For instance, Site 4, scored highly on all components, including a routinely captured periodontal diagnosis, comprehensive periodontal charts, and assessment of all three periodontal risk factors. Site 2 rarely captured a periodontal diagnosis and homecare and therefore had the lowest overall measure score. We anticipate that these measures can assist institutions in identifying specific areas for more in-depth inquiry and improvement. For instance, when critical components of periodontal health status and care are captured in the EHR, we can then use this data, such as a diagnosis and risk factors, to measure and infer the appropriateness of periodontal treatment and outcomes of that care.(38)

To date, the dental profession as a whole has not yet adopted a universal model of periodontal disease risk assessment, possibly due to challenges related to varying workflows, practice types, general agreement, adoption of EHRs, different types of EHRs, and continued challenges with interoperability. $(20,39)$ In our study, the research team identified and applied three factors known to be key to assessing periodontal disease risk: 1) diabetes status, 2) tobacco consumption, and 3) homecare status as measured by the presence of heavy plaque. We observed that diabetes status and tobacco use were generally well documented as the medical history forms are routinely updated. However, finding documentation of visible heavy plaque was more challenging. Some institutions incorporated a specific and structured question (e.g., "Does the patient have visible heavy plaque?") as part of their risk assessment form. While in other cases we extracted this information from a plaque score recorded as part of the periodontal exam. Our process and findings suggest the need for a standardized approach for assessing periodontal risk. A simple, universal risk assessment tool will benefit the profession,(22) and further help to direct appropriate care.(20,40) This can translate into creating a culture of quality improvement and accountability rather than a focus on treatment and payment.(41) Risk assessment measures also pave the way for the development of clinical decision support (CDS) tools,(42) and thus allowing for the provision of more timely information to clinicians and patients.(43)

According to the 1990-2010 Global Burden of Disease Study, periodontal disease ranks sixth in worldwide prevalence of Oral conditions in 2010 (44) and $11^{\text {th }}$ as a preventable global disease. Periodontal disease causes a significant economic burden, with an estimated 54 billion USD/year of lost productivity and 3.5 million years lived with disability. (45) Periodontal disease has a higher prevalence among the ageing population due to longer life spans and higher retention of natural dentition in this age group. With the pressure of an aging dentate population,(46) the rising understanding of the complexity of the disease,(47) and its relationship with chronic diseases,(48) there has been an increasing focus on understanding and managing the underlying risk factors.(49) Periodontal risk assessment strategies help evaluate and quantify risk,(50) thus providing internal benchmarks to assess periodontal care and evaluate disease progress or lack thereof in patients. $(22,50-52)$ The work conducted here provides an approach for better documenting the periodontal status of patients which is the first step before determining appropriate treatment pathways and for measuring the outcomes of care. $(20,39,53)$ Moreover, complete and accurate documentation in the EHR are the foundation for measurment in a value based care system, which dentistry undoubtedly will need to embrace.(54) 


\section{Limitations}

Some of the data used to measure documentation completeness are self-reported (e.g., diabetes status and tobacco use). Although, self-reported questionnaires have shown to have high sensitivity, they are potentially inaccurate due to their subjective nature.(55) Meaningful integration and coordination between medical and dental records may greatly reduce these challenges.(56) Our measure will also be challenging to implement in dental institutions who lack a robust informatics infrastructure including a common EHR and diagnostic terminology.

\section{Conclusion}

The study results highlight variation between dental institutions in capturing essential data to evaluate the quality of periodontal care. This work supports the use of EHRs, standardized dental diagnoses, and the potential for dental quality measures to assess appropriate periodontal disease evaluation before treatment in an effort to optimize outcomes of care.

\section{Declarations}

- Ethics approval and consent to participate

- We received Institutional Review Board (IRB) approval from all collaborating institutions before conducting our study. Our main IRB number is HSC-DB-14-1051 and name is U of Texas Health Science Center at Houston IRB, for the study titled - 'Implementing Dental Quality Measures in Practice'. Informed consent was not obtained as a waiver of authorization was received, as this study uses limited/deidentified data from Electronic Health Record (EHR) for secondary analysis. The research was conducted according to the principles outlined in the Helsinki Guidelines.

- Consent for publication

Not Applicable

\section{- Availability of data and materials}

Our legally binding data use agreements between the institutions do not allow public sharing of these data that are derived from electronic heath records. We are willing to consider reasonable requests for data access if the institutions agree and appropriate data use agreements are executed.

\section{- Competing interests}

Not Applicable

- Funding

National Institute of Dental \& Craniofacial Research of the National Institutes of Health under Award Number R01DE024166.

\section{- Authors' contributions}

Joanna Mullins: Methodology, Validation, Writing - Original/Review/Editing; Alfa Yansane: Formal analysis, Writing Original/Review/Editing ,Visualization; Shwetha V. Kumar: Writing - Original/Review/Editing; Suhasini Bangar: Writing 
- Review/Editing; Ana Neumann: Methodology, Validation, Writing - Review/Editing; Todd R. Johnson: Visualization, Writing - Review/Editing; Gregory W. Olson: Writing - Review/Editing; Krishna Kumar Kookal: Software, Data Curation, Writing - Review/Editing; Emily Sedlock: Writing - Review/Editing; Aram Kim: Writing - Review/Editing; Elizabeth Mertz: Writing - Review/Editing; Ryan Brandon: Methodology, Software, Data Curation, Formal analysis, Writing Review/Editing; Kristen Simmons: Conceptualization, Writing-Review, Editing; Joel M. White: Conceptualization, Methodology, Writing- Review \& Editing; Elsbeth Kalenderian: Conceptualization, Writing - Original/Review/Editing, Supervision, Funding acquisition; Muhammad F. Walji: Conceptualization, Writing - Original/Review/Editing, Supervision, Project administration, Funding acquisition

\section{- Acknowledgements}

Research reported in this publication was supported by the National Institute of Dental \& Craniofacial Research of the National Institutes of Health under Award Number R01DE024166. The content is solely the responsibility of the authors and does not necessarily represent the official views of the National Institutes of Health.

\section{- Authors' information (optional)}

Not applicable

\section{References}

1. Bloomrosen M, Detmer DE. Informatics, evidence-based care, and research; implications for national policy: a report of an American Medical Informatics Association health policy conference. Journal of the American Medical Informatics Association. 2010;17(2):115-23.

2. Timmermans S, Berg M. The gold standard: The challenge of evidence-based medicine and standardization in health care: Temple University Press; 2010.

3. Chassin MR, Loeb JM, Schmaltz SP, Wachter RM. Accountability measures-using measurement to promote quality improvement. Mass Medical Soc; 2010.

4. Jha AK, Joynt KE, Orav EJ, Epstein AM. The long-term effect of premier pay for performance on patient outcomes. New England Journal of Medicine. 2012;366(17):1606-15.

5. Dental Quality Alliance. About Dental Quality Alliance 2018 [cited 201812 December]. Available from: https://www.ada.org/en/science-research/dental-quality-alliance/about-dqa.

6. Herndon JB, Tomar SL, Catalanotto FA, Rudner N, Huang I-C, Aravamudhan K, et al. Measuring quality of dental care: caries prevention services for children. The Journal of the American Dental Association. 2015;146(8):581-91.

7. Herndon JB, Crall JJ, Aravamudhan K, Catalanotto FA, Huang IC, Rudner N, et al. Developing and testing pediatric oral healthcare quality measures. Journal of public health dentistry. 2015;75(3):191-201.

8. Alliance DQ. Electronic Pediatric Measures [cited 201928 January]. Available from:

https://www.ada.org/en/science-research/dental-quality-alliance/dqa-measure-activities/electronic-pediatricmeasures.

9. Simmons K, Gibson S, White JM. Drivers Advancing Oral Health in a Large Group Dental Practice Organization. Journal of Evidence Based Dental Practice. 2016;16:104-12.

10. Blumenthal D, Tavenner M. The "meaningful use" regulation for electronic health records. New England Journal of Medicine. 2010;363(6):501-4.

11. Kalenderian E, Walji M, Ramoni RB. "Meaningful use" of EHR in dental school clinics: how to benefit from the U.S. HITECH Act's financial and quality improvement incentives. J Dent Educ. 2013;77(4):401-15. 
12. Bhardwaj A, Ramoni R, Kalenderian E, Neumann A, Hebballi NB, White JM, et al. Measuring up: Implementing a dental quality measure in the electronic health record context. The Journal of the American Dental Association. 2016;147(1):35-40.

13. Neumann A, Kalenderian E, Ramoni R, Yansane A, Tokede B, Etolue J, et al. Evaluating quality of dental care among patients with diabetes: Adaptation and testing of a dental quality measure in electronic health records. The Journal of the American Dental Association. 2017;148(9):634-43. e1.

14. Kumar SV, Bangar S, Neumann A, Kookal KK, Yansane A, Tokede O, et al. Assessing the validity of existing dental sealant quality measures. The Journal of the American Dental Association. 2018;149(9):756-64. e1.

15. Dye BA. Global periodontal disease epidemiology. Periodontology 2000. 2012;58(1):10-25.

16. Eke PI, Dye BA, Wei L, Thornton-Evans GO, Genco RJ. Prevalence of periodontitis in adults in the United States: 2009 and 2010. Journal of dental research. 2012;91(10):914-20.

17. Lang NP, Suvan JE, Tonetti MS. Risk factor assessment tools for the prevention of periodontitis progression a systematic review. Journal of clinical periodontology. 2015;42:S59-S70.

18. Van Dyke TE, Sheilesh D. Risk factors for periodontitis. Journal of the International Academy of Periodontology. 2005;7(1):3-7.

19. De Wet L, Slot D, Van der Weijden G. Supportive periodontal treatment: Pocket depth changes and tooth loss. International journal of dental hygiene. 2018;16(2):210-8.

20. Thyvalikakath T, Song M, Schleyer T. Perceptions and attitudes toward performing risk assessment for periodontal disease: a focus group exploration. BMC oral health. 2018;18(1):90.

21. Trombelli L, Minenna L, Toselli L, Zaetta A, Checchi L, Checchi V, et al. Prognostic value of a simplified method for periodontal risk assessment during supportive periodontal therapy. Journal of clinical periodontology. 2017;44(1):51-7.

22. Mullins JM, Even JB, White JM. Periodontal Management by Risk Assessment: A Pragmatic Approach. Journal of Evidence Based Dental Practice. 2016;16:91-8.

23. Alliance DQ. Environmental Scan -Practice Based Measures [cited 201812 December]. Available from: https://www.ada.org/ /media/ADA/Science\%20and\%20Research/Files/DQA_2015_Environmental_Scan_PracticeBased_Measures.pdf?la=en.

24. Preshaw PM, editor Detection and diagnosis of periodontal conditions amenable to prevention. BMC oral health; 2015: BioMed Central.

25. Alliance DQ. Dental Quality Alliance-User Guide for Adult Measure Calculated using Administrative Claims Data [cited 201812 December]. Available from: https://www.ada.org/ /media/ADA/DQA/2019AdultMeasuresUserGuide.pdf?la=en.

26. Du M, Bo T, Kapellas K, Peres M. Prediction models for the incidence and progression of periodontitis: a systematic review. Journal of clinical periodontology. 2018.

27. Martin J, Mills S, Foley ME. Innovative Models of Dental Care Delivery and Coverage: Patient-Centric Dental Benefits Based on Digital Oral Health Risk Assessment. Dental Clinics of North America. 2018;62(2):319-25.

28. Page RC, Martin JA. Quantification of periodontal risk and disease severity and extent using the Oral Health Information Suite (OHIS). Periodontal Practice Today. 2007;4(3).

29. Lane BA, Luepke P, Chaves E, Maupome G, Eckert GJ, Blanchard S, et al. Assessment of the calibration of periodontal diagnosis and treatment planning among dental students at three dental schools. Journal of dental education. 2015;79(1):16-24. 
30. Genco RJ, Genco FD. Common risk factors in the management of periodontal and associated systemic diseases: the dental setting and interprofessional collaboration. J Evid Based Dent Pract. 2014;14 Suppl:4-16.

31. Mealey BL, Oates TW. Diabetes mellitus and periodontal diseases. J Periodontol. 2006;77(8):1289-303.

32. Lindskog S, Blomlof J, Persson I, Niklason A, Hedin A, Ericsson L, et al. Validation of an algorithm for chronic periodontitis risk assessment and prognostication: risk predictors, explanatory values, measures of quality, and clinical use. J Periodontol. 2010;81(4):584-93.

33. Neumann A, Kumar S, Bangar S, Kookal KK, Spallek H, Tokede O, et al. Tobacco screening and cessation efforts by dental providers: A quality measure evaluation. Journal of public health dentistry. 2019;79(2):93-101.

34. Neumann A, Obadan-Udoh E, Bangar S, Kumar SV, Tokede O, Kim A, et al. Number of Pregnant Women at Four Dental Clinics and the Care They Received: A Dental Quality eMeasure Evaluation. Journal of Dental Education. 2019:JDE. 019.123.

35. Cunningham $M$, editor More than just the kappa coefficient: a program to fully characterize inter-rater reliability between two raters. SAS global forum; 2009; Gaylord National Resort and Convention Center, Washington, DC.

36. Kalenderian E, Ramoni RL, White JM, Schoonheim-Klein ME, Stark PC, Kimmes NS, et al. The development of a dental diagnostic terminology. J Dent Educ. 2011;75(1):68-76.

37. Yansane A, Tokede O, White J, Etolue J, McClellan L, Walji M, et al. Utilization and Validity of the Dental Diagnostic System over Time in Academic and Private Practice. JDR Clin Trans Res. 2019;4(2):143-50.

38. Kalenderian E, Tokede B, Ramoni R, Khan M, Kimmes N, White J, et al. Dental clinical research: an illustration of the value of standardized diagnostic terms. Journal of public health dentistry. 2016;76(2):152-6.

39. Thyvalikakath T, Song M, Schleyer T. Perceptions and attitudes toward performing risk assessment for periodontal disease: a focus group exploration. BMC Oral Health [Internet]. 2018 2018/05//; 18(1):[90 p.]. Available from: http://europepmc.org/abstract/MED/29783966 https://doi.org/10.1186/s12903-018-05502 http://europepmc.org/articles/PMC5963023 http://europepmc.org/articles/PMC5963023?pdf=render.

40. Page RC, Krall EA, Martin J, Mancl L, Garcia RI. Validity and accuracy of a risk calculator in predicting periodontal disease. Journal of the American Dental Association (1939). 2002;133(5):569-76.

41. Lee $\mathrm{H}$, Chalmers $\mathrm{NI}$, Brow A, Boynes $\mathrm{S}$, Monopoli M, Doherty M, et al. Person-centered care model in dentistry. BMC oral health. 2018;18(1):198-

42. Mertz E, Wides C, White J. Clinician attitudes, skills, motivations and experience following the implementation of clinical decision support tools in a large dental practice. The journal of evidence-based dental practice. 2017;17(1):1-12.

43. Douglass CW. Risk assessment and management of periodontal disease. Journal of the American Dental Association. 2006;137 Suppl:27S-32S.

44. Marcenes W, Kassebaum NJ, Bernabé E, Flaxman A, Naghavi M, Lopez A, et al. Global burden of oral conditions in 1990-2010: a systematic analysis. J Dent Res. 2013;92(7):592-7.

45. Tonetti MS, Jepsen S, Jin L, Otomo-Corgel J. Impact of the global burden of periodontal diseases on health, nutrition and wellbeing of mankind: A call for global action. Journal of clinical periodontology. 2017;44(5):456-62.

46. Ettinger RL. The unique oral health needs of an aging population. Dental Clinics of North America. 1997;41(4):63349.

47. Dall TM, Gallo PD, Chakrabarti R, West T, Semilla AP, Storm MV. An aging population and growing disease burden will require alarge and specialized health care workforce by 2025. Health affairs. 2013;32(11):2013-20.

48. Ettinger RL. Oral health and the aging population. The Journal of the American Dental Association. 2007;138:S5S6.

Page $10 / 14$ 
49. Ogawa H, Yoshihara A, Hirotomi T, Ando Y, Miyazaki H. Risk factors for periodontal disease progression among elderly people. Journal of clinical periodontology. 2002;29(7):592-7.

50. Lang NP, Suvan JE, Tonetti MS. Risk factor assessment tools for the prevention of periodontitis progression a systematic review. J Clin Periodontol. 2015;42 Suppl 16:S59-70.

51. Page RC, Martin JA, Loeb CF. The Oral Health Information Suite (OHIS): Its Use in the Management of Periodontal Disease. Journal of Dental Education. 2005;69(5):509-20.

52. Martin RCPaJA. Quantification of periodontal risk and disease severity and extent using the Oral Health Information Suite (OHIS). Perio Practice Today. 2007(Nr.3).

53. Mertz E, Bolarinwa O, Wides C, Gregorich S, Simmons K, Vaderhobli R, et al. Provider Attitudes Toward the Implementation of Clinical Decision Support Tools in Dental Practice. The journal of evidence-based dental practice. 2015;15(4):152-63.

54. Advocacy CfM. White Paper Stresses Importance of Oral Health Care Benefit for Older Adults 2018 [cited 2019 9/02]. Available from: https://www.medicareadvocacy.org/white-paper-stresses-importance-of-oral-health-carebenefit-for-older-adults/.

55. Okura Y, Urban LH, Mahoney DW, Jacobsen SJ, Rodeheffer RJ. Agreement between self-report questionnaires and medical record data was substantial for diabetes, hypertension, myocardial infarction and stroke but not for heart failure. Journal of clinical epidemiology. 2004;57(10):1096-103.

56. Donoff B, McDonough JE, Riedy CA. Integrating oral and general health care. New England Journal of Medicine. 2014;371(24):2247-9.

\section{Tables}

Table 1: Description of measure validity using manual reviewed charts as gold standard.

\begin{tabular}{|lllll|}
\hline & Site 1 & Site 2 & Site 3 & Site 4 \\
\hline Kappa & 0.8960 & - & 0.8960 & 1.000 \\
\hline Sensitivity & $100 \%$ & $100 \%$ & $94.2 \%$ & $100 \%$ \\
\hline Specificity & $95.8 \%$ & $99.7 \%$ & $97.2 \%$ & $100 \%$ \\
\hline PPV & $83.7 \%$ & $50 \%$ & $94.1 \%$ & $100 \%$ \\
\hline NPV & $100 \%$ & $100 \%$ & $97.2 \%$ & $100 \%$ \\
\hline
\end{tabular}

Table 2: Overall and component measure scores across the 4 sites. ( $n=$ number of patients meeting the denominator criteria in the respective reporting year) 


\begin{tabular}{|c|c|c|c|c|c|c|c|c|}
\hline & & $\begin{array}{l}\text { Overall } \\
\text { Measure }\end{array}$ & $\begin{array}{l}\text { A. Perio } \\
\text { Diagnosis }\end{array}$ & $\begin{array}{l}\text { B. Perio } \\
\text { Chart }\end{array}$ & $\begin{array}{l}\text { C. Perio } \\
\text { Risk }\end{array}$ & $\begin{array}{l}\text { C.1 } \\
\text { Homecare }\end{array}$ & $\begin{array}{l}\text { C. } 2 \\
\text { Diabetes }\end{array}$ & $\begin{array}{l}\text { C.3 } \\
\text { Tobacco }\end{array}$ \\
\hline \multirow[t]{4}{*}{2015} & $\begin{array}{l}\text { Site } 1 \\
(n=6825)\end{array}$ & $16.44 \%$ & $43.22 \%$ & $54.90 \%$ & $26.81 \%$ & $33.44 \%$ & $62.68 \%$ & $62.36 \%$ \\
\hline & $\begin{array}{l}\text { Site } 2 \\
(n=3590)\end{array}$ & $0.64 \%$ & $3.26 \%$ & $32.67 \%$ & $3.59 \%$ & $4.48 \%$ & $86.24 \%$ & $78.61 \%$ \\
\hline & $\begin{array}{l}\text { Site } 3 \\
(11296)\end{array}$ & $29.57 \%$ & $48.57 \%$ & $66.47 \%$ & $49.96 \%$ & $55.21 \%$ & $69.87 \%$ & $69.65 \%$ \\
\hline & $\begin{array}{l}\text { Site } 4 \\
(142690)\end{array}$ & $99.22 \%$ & $99.90 \%$ & $99.40 \%$ & $99.82 \%$ & $99.86 \%$ & $99.88 \%$ & $99.86 \%$ \\
\hline \multirow[t]{4}{*}{2016} & $\begin{array}{l}\text { Site } 1 \\
(n=7379)\end{array}$ & $22.46 \%$ & $46.54 \%$ & $59.52 \%$ & $36.56 \%$ & $43.56 \%$ & $66.57 \%$ & $66.36 \%$ \\
\hline & $\begin{array}{l}\text { Site } 2 \\
(n=3762)\end{array}$ & $1.97 \%$ & $11.99 \%$ & $34.18 \%$ & $4.31 \%$ & $5.53 \%$ & $84.34 \%$ & $76.56 \%$ \\
\hline & $\begin{array}{l}\text { Site 3 } \\
(n=12279)\end{array}$ & $26.58 \%$ & $43.85 \%$ & $65.65 \%$ & $51.20 \%$ & $56.16 \%$ & $69.62 \%$ & $69.39 \%$ \\
\hline & $\begin{array}{l}\text { Site } 4 \\
(n=151824)\end{array}$ & $99.07 \%$ & $99.90 \%$ & $99.25 \%$ & $99.81 \%$ & $99.83 \%$ & $99.85 \%$ & $99.86 \%$ \\
\hline \multirow[t]{4}{*}{2017} & $\begin{array}{l}\text { Site } 1 \\
(n=6853)\end{array}$ & $23.96 \%$ & $47.23 \%$ & $62.95 \%$ & $40.07 \%$ & $47.05 \%$ & $69.71 \%$ & $70.26 \%$ \\
\hline & $\begin{array}{l}\text { Site } 2 \\
(n=3938)\end{array}$ & $0.89 \%$ & $10.46 \%$ & $36.52 \%$ & $4.06 \%$ & $5.13 \%$ & $82.58 \%$ & $75.24 \%$ \\
\hline & $\begin{array}{l}\text { Site 3 } \\
(12989)\end{array}$ & $24.92 \%$ & $42.01 \%$ & $66.90 \%$ & $46.24 \%$ & $51.67 \%$ & $68.33 \%$ & $68.07 \%$ \\
\hline & $\begin{array}{l}\text { Site } 4 \\
(166139)\end{array}$ & $99.34 \%$ & $99.90 \%$ & $99.53 \%$ & $99.80 \%$ & $99.81 \%$ & $99.83 \%$ & $99.83 \%$ \\
\hline \multirow[t]{4}{*}{2018} & $\begin{array}{l}\text { Site } 1 \\
(n=6452)\end{array}$ & $20.47 \%$ & $43.71 \%$ & $60.63 \%$ & $37.21 \%$ & $45.29 \%$ & $67.37 \%$ & $68.92 \%$ \\
\hline & $\begin{array}{l}\text { Site } 2 \\
(n=4411)\end{array}$ & $0.97 \%$ & $8.41 \%$ & $36 \%$ & $3.36 \%$ & $4.87 \%$ & $83.38 \%$ & $74.65 \%$ \\
\hline & $\begin{array}{l}\text { Site 3 } \\
(n=13146)\end{array}$ & $22.27 \%$ & $37.86 \%$ & $69.57 \%$ & $46.18 \%$ & $52.69 \%$ & $67.62 \%$ & $67.12 \%$ \\
\hline & $\begin{array}{l}\text { Site } 4 \\
(n=177441)\end{array}$ & $99.49 \%$ & $99.91 \%$ & $99.66 \%$ & $99.83 \%$ & $99.84 \%$ & $99.84 \%$ & $99.85 \%$ \\
\hline
\end{tabular}

Figures 


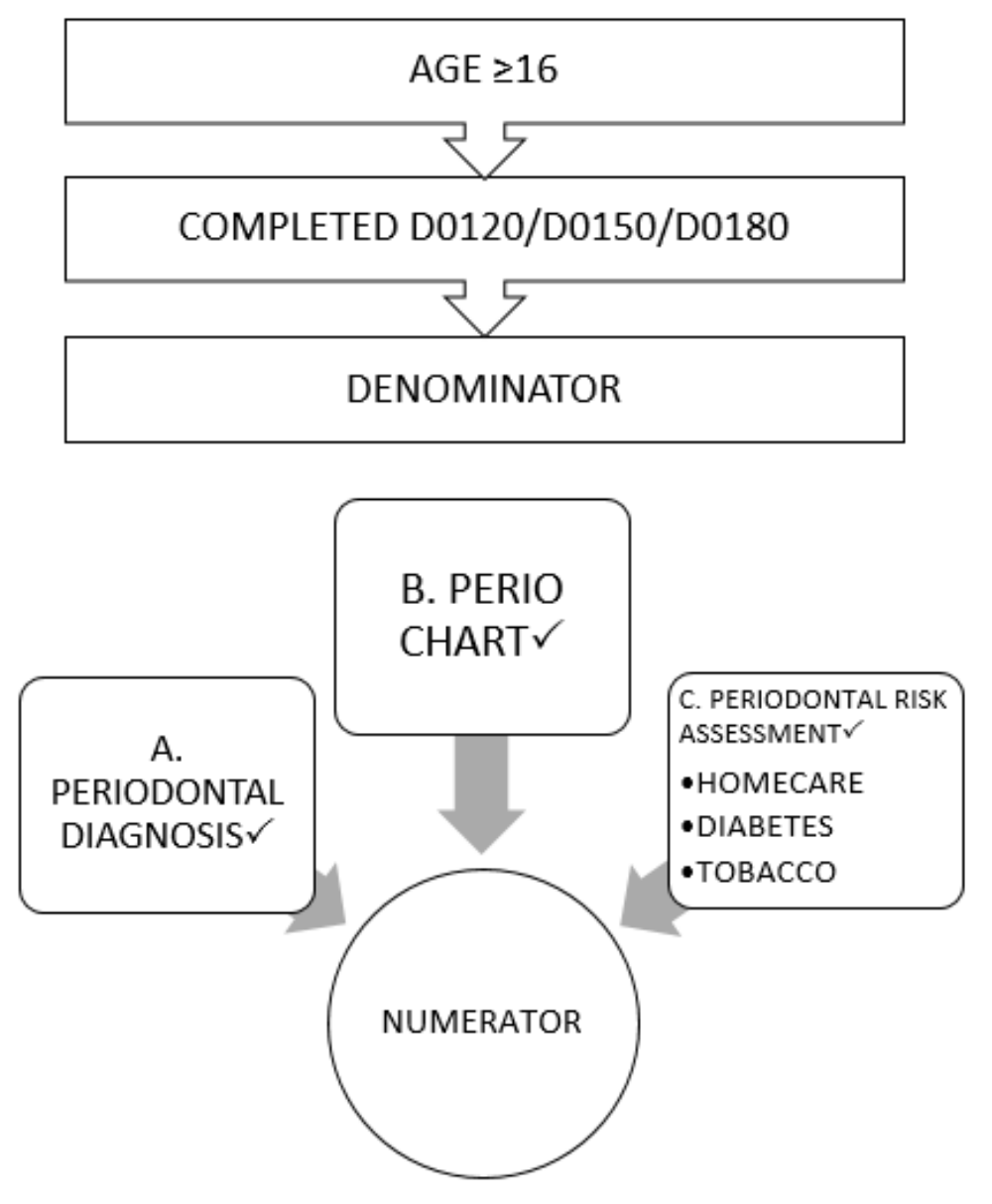

Figure 1

a: Process map to determine the denominator b: Process map to determine the numerator 
Overall Measure score across four sites (2015-2018)

$100.00 \%$ $\begin{array}{lll}-99.22 \% & 99.07 \% & 99.34 \%\end{array}$

$80.00 \%$

$60.00 \%$

$40.00 \%$

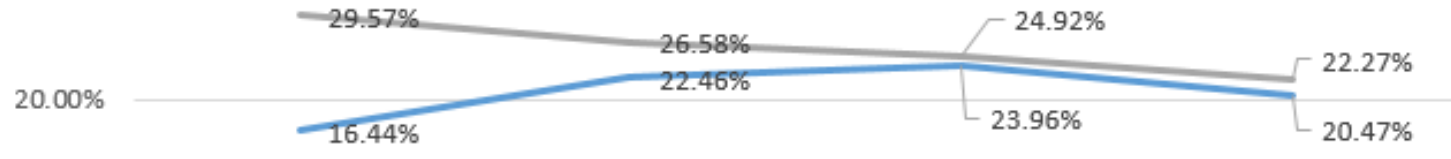

$0.00 \%$
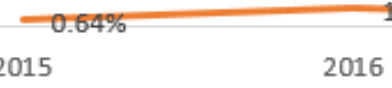

$0.89 \%$

$0.97 \%$

2017

2018

$\longrightarrow$ Site1 $\longrightarrow$ Site2 Site3 Site4

\section{Figure 2}

Comparison of measure score (automated vs manual) across the four sites for the year 2015. 